\title{
Turkish Compliance and Adaptation of EULAR 2013 Recommendations for the Management of Rheumatoid Arthritis with Synthetic and Biological Disease-Modifying Antirheumatic Drugs: Expert Opinion of TLAR
}

\author{
Şebnem ATAMAN, ${ }^{1}$ Zühre SARI SÜRMELİ, ${ }^{1}$ İsmihan SUNAR, ${ }^{1}$ Erhan ÖZDEMİREL, ${ }^{1}$ Ayşen AKINCI, ${ }^{2}$ \\ Hatice BODUR, ${ }^{3}$ Özgür AKGÜL, ${ }^{4}$ Lale ALTAN, ${ }^{5}$ Zuhal ALTAY, ${ }^{6}$ Figen AYHAN, ${ }^{7}$ Murat BİRTANE, ${ }^{8}$ \\ Derya SOY BUĞDAYCI, ${ }^{9}$ Erhan ÇAPKIN,${ }^{10}$ Lale CERRAHOĞLU, ${ }^{4}$ Mehmet Tuncay DURUÖZ, ${ }^{11}$ \\ Rezzan GÜNAYDIN, ${ }^{12}$ Zafer GÜNENDİ, ${ }^{13}$ Gülcan GÜRER,,${ }^{14}$ Ajda BAL, ${ }^{15}$ Cahit KAÇAR, ${ }^{16}$ \\ Ece KAPTANOĞLU, ${ }^{17}$ Taciser KAYA, ${ }^{18}$ Hilal KOCABAŞ, ${ }^{19}$ Nurdan KOTEVOĞLU, ${ }^{20}$ Kemal NAS, ${ }^{21}$ \\ Aylin REZVANI ${ }^{22}$ Nesrin ŞEN, ${ }^{23}$ Ömer Faruk ŞENDUR, ${ }^{14}$ Peyman YALÇIN ${ }^{1}$

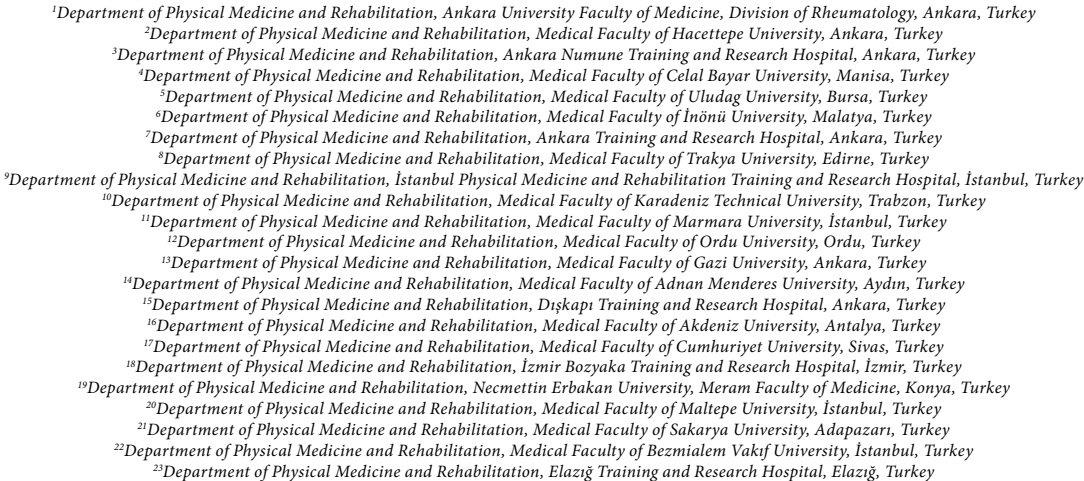

\section{ABSTRACT}

Objectives: This study aims to report Turkish League Against Rheumatism's assessment on the compliance of European League Against Rheumatism 2013 treatment recommendations for rheumatoid arthritis with practices in Turkish rheumatology clinics and adaptations for Turkey.

Materials and methods: Members of Turkish League Against Rheumatism and one rheumatoid arthritis patient voted for the 2013 recommendations of the European League Against Rheumatism for treatment of rheumatoid arthritis in two sessions. An item was changed and voted again only if at least $70 \%$ of participants wanted a change. Strength of recommendations was calculated for the items. Strength of recommendations for the changed items in the first and second voting rounds was compared by Wilcoxon signed-rank test. In case of significant difference, the item with higher strength of recommendation was accepted. In case of no difference, the changed item was selected.

Results: Three overarching principles and fourteen recommendations were assessed among which the three overarching principles were changed emphasizing the importance of physiatrists as well as rheumatologists for taking care of the patients. Third item was changed by adding composite indices for assessing disease activity. In the ninth recommendation, rituximab was suggested as a first line drug independent of situations like latent tuberculosis or lymphoma, etc. In the $11^{\text {th }}$ recommendation, unlike European League Against Rheumatism, our committee did not suggest any thought about tofacitinib, as then it had not been approved in Turkey. Remaining principles were accepted as the same.

Conclusion: Expert opinion of Turkish League Against Rheumatism for treatment of rheumatoid arthritis patients was formed for practices in Turkish clinics.

Keywords: Biologic disease modifying anti-rheumatic drugs; rheumatoid arthritis; synthetic disease modifying anti-rheumatic drugs; treatment recommendations. 
Disease modifying anti-rheumatic drugs (DMARDs) are used in the management of rheumatoid arthritis (RA). These drugs ameliorate signs and symptoms, pain and functional disability, quality of life, and hamper structural joint damage. ${ }^{1}$ Smolen et al. ${ }^{1}$ proposed a new nomenclature for classification of DMARDs so that they are now divided into two main classes: synthetic (sDMARDs) and biological DMARDs (bDMARDs). Synthetic DMARDs are then divided into two groups as conventional synthetic (csDMARD) and targeted synthetic (tsDMARD) DMARDs. Conventional sDMARDs comprise methotrexate (MTX), sulfasalazine and leflunomide. Tofacitinib is a newly developed synthetic DMARD which targets janus kinases, thus it is called as tsDMARD. Tumor necrosis factor (TNF) inhibitors [infliximab (IFX), etanercept (ETN), adalimumab (ADA), golimumab, and certolizumab pegol], abatacept (inhibitor of $\mathrm{T}$ cell costimulation), rituximab (the monoclonal antibody against CD20 of B cells), tocilizumab (TCZ) [monoclonal antibody of the interleukin 6 (IL-6) receptor], and anakinra (IL-1 inhibitor) are known as biologic originator (bo) molecules. Biosimilars are named as bsDMARDs (eg: bs-IFX). ${ }^{2}$

Up to date, The European League Against Rheumatism (EULAR) has published several recommendations about treatment of RA. In 2011, for the first time, Turkish League Against Rheumatism (TLAR) adapted the EULAR 2010 recommendations for the management of RA with synthetic and biological DMARDs. ${ }^{3}$ Thus, in this study, we aimed to report TLAR's assessment on the compliance of EULAR 2013 treatment recommendations for $\mathrm{RA}$ with practices in Turkish rheumatology clinics and adaptations for Turkey. This project is the second adaptation study of EULAR recommendations for management of RA for Turkish rheumatologists and physiatrists.

\section{MATERIALS AND METHODS}

We sent an email to the members of TLAR and mentioned about the project of "Turkish Compliance and Adaptation of EULAR 2013 Recommendations for the Management of Rheumatoid Arthritis with Synthetic and Biological Disease-Modifying Antirheumatic Drugs: TLAR Expert Opinion" and requested them to fill the attached survey regarding if they would want to take part in the project. In this survey, the participants were asked to indicate their published studies about RA, the number of RA patients that they examine or whose examination they participate as a consultant in one week. To eliminate any superiority among clinics, one or two persons were chosen from each clinic during the selection of the committee members. From a total of 23 medical centers, two persons were selected per center only from three centers. From the members who filled the survey, 26 participants were selected as experts of RA and invited to a meeting on May 26, 2014. Three rheumatology fellows and one patient with RA were also involved in this project. The patient participated actively in the voting process together with the committee members. The rheumatology fellows had active roles in gathering the data, preparing and analyzing the survey questions and doing similar activities. Before the meeting, the paper of EULAR 2013 treatment recommendations was e-mailed to the participants. ${ }^{4}$ The voting of the recommendations was held two times; a 0-10 numeric scale on an electronic keypad was used for the voting processes during the meeting. The first voting was held just after the opening of the meeting and EULAR 2013 RA treatment recommendations were voted one by one. The rate of participation and the strength of recommendations were determined for each recommendation. In the second voting process, every recommendation was discussed individually and if any change about a recommendation was proposed, this change was accepted only if there was at least $70 \%$ approval in favor of change by the experts and then the changed items were voted again. Strength of recommendation was calculated for each item for the first voting and for the changed items for the second voting. Strength of recommendations of the changed items was compared using Wilcoxon-signed rank test to demonstrate any statistically significant difference between the two voting rounds. In case of any statistically significant change for an item between two voting rounds, the one that had the higher strength of recommendation was accepted. If there was no statistically significant difference, we accepted the item that was changed. The Wilcoxon-signed rank test results and strength of recommendations of the changed items were given in Table 1 and 2 . 
Table 1. Wilcoxon signed-rank test results and strength of recommendations of changed items $(n=26)$

\begin{tabular}{|c|c|c|c|c|}
\hline & Mean \pm SD & Min.-Max. & Z & $p^{*}$ \\
\hline $\mathrm{A} 1$ & $8.77 \pm 2.065$ & $2-10$ & \multirow{2}{*}{$-2.844^{b}$} & \multirow{2}{*}{0.004} \\
\hline A2 & $9.65 \pm 0.892$ & $6-10$ & & \\
\hline B1 & $8.31 \pm 2.131$ & $1-10$ & \multirow{2}{*}{$-3.562^{b}$} & \multirow{2}{*}{0.000} \\
\hline B2 & $9.73 \pm 0.604$ & $8-10$ & & \\
\hline $\mathrm{C} 1$ & $9.00 \pm 1.265$ & $6-10$ & \multirow{2}{*}{$-2.530^{\mathrm{b}}$} & \multirow{2}{*}{0.011} \\
\hline $\mathrm{C} 2$ & $9.31 \pm 1.192$ & $5-10$ & & \\
\hline \multicolumn{5}{|c|}{$\begin{array}{l}\text { SD: Standard deviation; Min.: Minimum; Max.: Maximum; * Asymp. Sig } \\
\text { (2-tailed); a: Wilcoxon signed-rank test; b: Based on negative ranks; } \text { : Based } \\
\text { on positive ranks; } 1 \text { : First voting; 2: Second voting; } \mathrm{p}<0.05 \text { : Statistically } \\
\text { significant change. }\end{array}$} \\
\hline
\end{tabular}

We also compared the percentage of votes between EULAR's self-voting and our voting of the original EULAR recommendations by using two sample t-test. The results were given in Table 3 .

\section{RESULTS}

The recommendations are summarized in Table 4. We changed three overarching principles and three of the recommendations, numbers of which are 3, 9 and 11. Only the changed items will be explained here. The remaining items were accepted identically with EULAR's. ${ }^{4}$

\section{Overarching principles}

A) This principle was changed as "Treatment of RA patients should aim at the best care and must be based on a shared decision between the
Table 2. Wilcoxon signed-rank test results and strength of recommendations of changed items $(n=26)$

\begin{tabular}{|c|c|c|c|c|}
\hline & Mean \pm SD & Min.-Max. & Z & $p^{*}$ \\
\hline 31 & $9.5 \pm 0.906$ & $7-10$ & \multirow{2}{*}{$1.725^{c}$} & \multirow{2}{*}{0.084} \\
\hline $3_{2}$ & $9.15 \pm 1.870$ & $2-10$ & & \\
\hline $4_{1}$ & $9.85 \pm 0.464$ & $8-10$ & \multirow{2}{*}{$2.539^{c}$} & \multirow{2}{*}{0.011} \\
\hline $4_{2}$ & $8.77 \pm 2.160$ & $2-10$ & & \\
\hline $9_{1}$ & $9.12 \pm 1.071$ & $7-10$ & \multirow{2}{*}{$-0.957^{b}$} & \multirow{2}{*}{0.339} \\
\hline $9_{2}$ & $9.23 \pm 1.681$ & $2-10$ & & \\
\hline $11_{1}$ & $8.15 \pm 2.111$ & $1-10$ & \multirow{2}{*}{$-3.327^{b}$} & \multirow{2}{*}{0.001} \\
\hline $11_{2}$ & $9.00 \pm 2.135$ & $1-10$ & & \\
\hline
\end{tabular}

patient and the rheumatologist or the physiatrist." instead of the original item mentioning a shared decision between the patient and the rheumatologist only. The altered principle was widely approved but minor alterations were suggested: two participants proposed to add the term "immunologists" to this item, since in Turkey RA patients are treated by all of these mentioned experts. However, since the majority did not agree on this proposal, the term 'immunologist' was not added.

The strength of recommendation increased from $8.77 \pm 2.065$ to $9.65 \pm 0.892$ after the revision.

B) This principle was also changed as "Rheumatologists and the physiatrists are

Table 3. Percentage of votes and strength of recommendation values for items

\begin{tabular}{|c|c|c|c|c|c|}
\hline \multirow[b]{2}{*}{ Item no } & \multicolumn{2}{|c|}{ EULAR original } & \multicolumn{2}{|c|}{ First voting of EULAR's recommendations } & \multirow[b]{2}{*}{$p$} \\
\hline & Percent of votes & Strength of recommendation & Percent of votes & Strength of recommendation & \\
\hline A & 100 & $9.8 \pm 0.9$ & 90 & $8.7 \pm 2.0$ & $<0.001$ \\
\hline B & 100 & $9.8 \pm 0.5$ & 78 & $8.3 \pm 2.1$ & $<0.001$ \\
\hline C & 100 & $9.6 \pm 0.6$ & 97 & $9.0 \pm 1.2$ & 0.026 \\
\hline 1 & 97 & $9.8 \pm 0.5$ & 100 & $9.8 \pm 0.5$ & 0.453 \\
\hline 2 & 100 & $9.6 \pm 0.7$ & 100 & $9.8 \pm 0.4$ & 1.000 \\
\hline 3 & 100 & $9.5 \pm 1.0$ & 100 & $9.5 \pm 0.5$ & 1.000 \\
\hline 4 & 100 & $9.6 \pm 0.9$ & 100 & $9.8 \pm 0.4$ & 1.000 \\
\hline 5 & 87 & $9.0 \pm 1.7$ & 96 & $9.2 \pm 1.1$ & 0.131 \\
\hline 6 & 100 & $9.5 \pm 0.8$ & 100 & $9.5 \pm 0.8$ & 1.000 \\
\hline 7 & 73 & $8.9 \pm 1.2$ & 100 & $9.3 \pm 1.0$ & $<0.001$ \\
\hline 8 & 100 & $8.9 \pm 1.3$ & 96 & $8.9 \pm 1.2$ & 0.026 \\
\hline 9 & 90 & $9.2 \pm 1.2$ & 100 & $9.1 \pm 1.0$ & 0.065 \\
\hline 10 & 97 & $9.4 \pm 0.8$ & 96 & $9.2 \pm 1.6$ & 0.547 \\
\hline 11 & 90 & $7.6 \pm 1.8$ & 88 & $8.1 \pm 2.1$ & 0.489 \\
\hline 12 & 100 & $8.7 \pm 1.8$ & 100 & $9.2 \pm 1.0$ & 1.000 \\
\hline 13 & 100 & $8.9 \pm 1.0$ & 96 & $9.6 \pm 0.9$ & 0.026 \\
\hline 14 & 100 & $9.7 \pm 0.7$ & 100 & $9.8 \pm 0.5$ & 1.000 \\
\hline
\end{tabular}


Table 4. Amendment by Turkish League Against Rheumatism of European League Against Rheumatism 2013 treatment recommendations for management of rheumatoid arthritis with synthetic and biological disease modifying antirheumatic drugs ${ }^{[4]}$

\section{Overarching principles}

A. Treatment of RA patients should aim at the best care and must be based on a shared decision between the patient and the rheumatologist or the physiatrist.

B. Rheumatologists and physiatrists are the specialists who should primarily care for RA patients.

C. Rheumatoid arthritis incurs high individual, societal and medical costs, all of which should be considered in its management by the treating rheumatologist or the physiatrist.

\section{Recommendations}

1. Therapy with DMARDs should be started as soon as the diagnosis of RA is made.

2. Treatment should be aimed at reaching a target of remission or low disease activity in every patient.

3. Monitoring should be frequent in active disease (every 1-3 months); if there is no improvement with regard to composite indices by at most three months after the start of treatment or the target has not been reached by six months, therapy should be adjusted.

4. Methotrexate should be part of the first treatment strategy in patients with active RA.

5. In cases of MTX contraindications (or early intolerance), leflunomid or sulfasalazine should be considered as part of the (first) treatment strategy.

6. In DMARD-naive patients, irrespective of the addition of glucocorticoids, csDMARD monotherapy or combination therapy of csDMARDs should be used.

7. Low dose glucocorticoids should be considered as part of the initial treatment strategy (in combination with one or more csDMARDs) for up to six months, but should be tapered as rapidly as clinically feasible.

8. If the treatment target is not achieved with the first DMARD strategy, in the absence of poor prognostic factors, change to another csDMARD strategy should be considered; when poor prognostic factors are present, addition of a bDMARD should be considered.

9. In patients responding insufficiently to MTX and/or other csDMARD strategies, with or without glucocorticoids, bDMARDs (TNF inhibitors*, abatacept, rituximab or tocilizumab) should be commenced with MTX

10. If a first bDMARD has failed, the patients should be treated with another bDMARD; if a first TNF inhibitor therapy has failed, patients may receive another TNF inhibitor* or a biological agent with another mode of action

11. Although EULAR has an opinion regarding tofacitinib, our committee did not suggest any thoughts about tofacitinib as it has not yet been approved in our country.

12. If a patient is in a persistent remission after having tapered glucocorticoids, one can consider tapering \# bDMARDs $\S$, especially if this treatment is combined with a csDMARD.

13. In cases of sustained long-term remission, cautious reduction of the csDMARD dose should be considered, as a shared decision between patient and physician.

14. When therapy needs to be adjusted, factors apart from disease activity, such as progression of structural damage, comorbidities and safety issues, should be taken into account.

" TNF inhibitors: Infliximab, etanercept, adalimumab, golimumab, certolizumab pegol, and biosimilars; ₹ Tapering means either dose reduction or extension of intervals between drug applications; \& Most data are derived from studies with TNF inhibitors, but reduction of dose or extension of the intervals can also be applied to other biological agents with mechanisms of action different from TNF inhibitors': DMARD: Diseasemodifying antirheumatic drug; MTX: Methotrexate; RA: Rheumatoid arthritis; TNF: Tumor necrosis factor. the specialists who should primarily care for RA patients," adding and emphasizing the physiatrists' role in the management of RA patients. As depicted in 2013 Update of the EULAR Recommendations, the term "primarily" means that, in the absence of rheumatologists or physiatrists, other experienced physicians may follow-up RA patients. Secondly, as remarked by our committee too, it implies the requirement of educated health staff such as rheumatology nurses, physiotherapists, and occupational therapists besides the physicians.

The strength of recommendation increased from $8.31 \pm 2.131$ to $9.73 \pm 0.604$ after the revision.

C) This item was changed as "RA incurs high individual, societal and medical costs, all of which should be considered in its management by the treating rheumatologist or physiatrist." Also in this item, the role of physiatrists was emphasized.

In Consensus Recommendations from The Turkish League Against Rheumatism which was published in 2011, the main principle A had focused on the role of physiatrists as well as rheumatologists. This article stated that rheumatology divisions within the physical medicine and rehabilitation clinics were founded in 1983 for the first time and that The Ministry of Health and the Council of Higher Education approved rheumatology subspecialties of both internal medicine and physical medicine and rehabilitation since then. ${ }^{3}$

The strength of recommendation increased from $9.00 \pm 1.265$ to $9.31 \pm 1.192$ after the mentioned change.

Also in these overarching principles, there were statistically significant differences in the percentage of votes between EULAR's voting and our voting of EULAR (Table 3).

\section{Recommendations}

The recommendations are summarized by an algorithm shown in Figure 1.

The first two recommendations were approved exactly the same.

3. This principle was changed as "Monitoring should be frequent in active disease (every 1-3 months); if there is no improvement with regard 


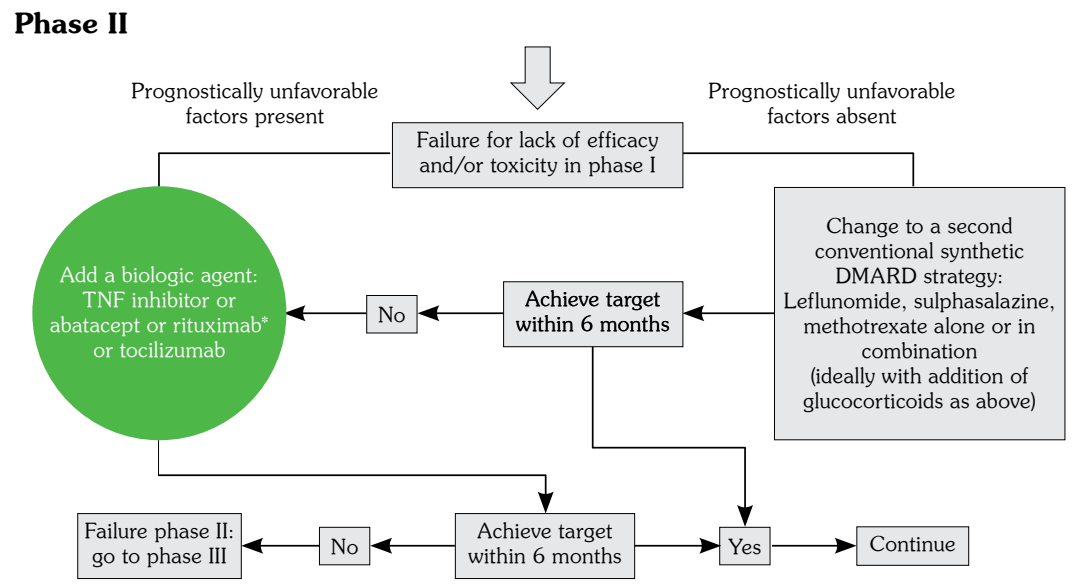

Phase III

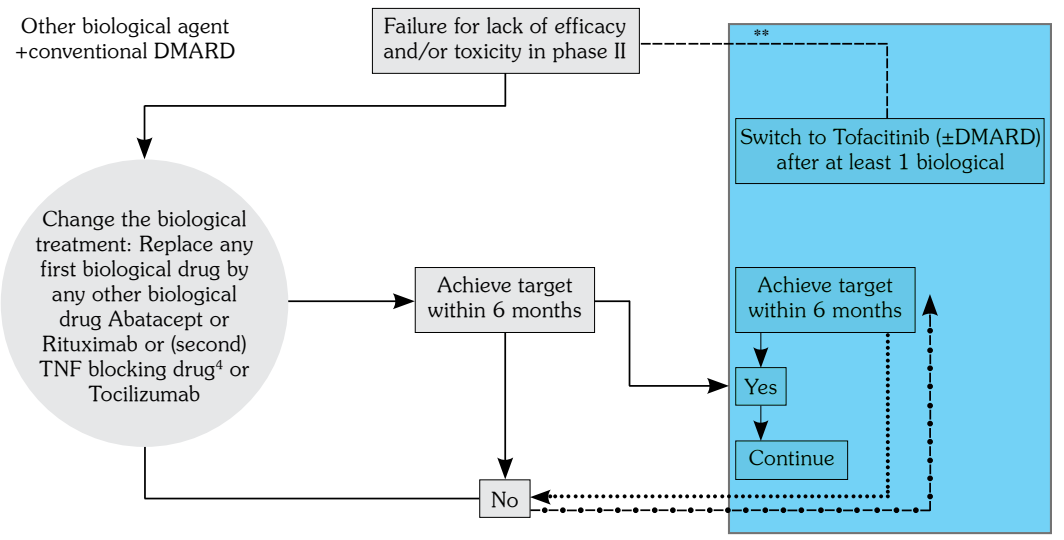

Figure 1. Changes in algoritm based on 2013 European League Against Rheumatism recommendations on rheumatoid arthritis management by the expert opinion of Turkish League Against Rheumatism. (Amendment from European League Against Rheumatism recommendations for the management of rheumatoid arthritis with synthetic and biological disease-modifying antirheumatic drugs: 2013 update). ${ }^{[4]}$ The shapes and writings colored in grey correspond to the unchanged items of European League Against Rheumatism's 2013 treatment recommendations of rheumatoid arthritis by Turkish League Against Rheumatism. The green wording corresponds to the changes made by Turkish League Against Rheumatism expert opinion. The blue one corresponds that there is not any idea by Turkish League Against Rheumatism expert opinion.

* In European League Against Rheumatism 2013 recommendations, after failure of csDMARD strategies including MTX, rituximab use was restricted only in certain circumstances (like latent tuberculosis, lymphoma, demyelinating disease history, or having malignancy). ${ }^{[5,6]}$ However, in Turkish League Against Rheumatism recommendations, rituximab was approved as the first line drug after csDMARD failure independent of these circumstances.

** Although in European League Against Rheumatism 2013 recommendations, there was an opinion regarding the use of tofacitinib, the expert committee of Turkish League Against Rheumatism did not want to suggest any suggestion about tofacitinib as this drug had not been approved in our country yet during the meeting of the Turkish League Against Rheumatism expert opinion. (After the meeting, tofacitinib use has been approved by our social security institution but the use of this drug will remain limited until it starts to be produced in Turkey). 
to composite indices by at most three months after the start of treatment or the target has not been reached by six months, therapy should be adjusted." The term "composite indices" was added to the original principle.

The strength of this recommendation decreased to $9.15 \pm 1.870$ from 9.50 after the revision; however, the revised form was accepted due to proposal of $70 \%$ of the participants since there was no statistically significant difference between first and second forms of the principle.

4. "Methotrexate should be part of the first treatment strategy in patients with active RA".

With regard to this statement, we made a change at first with $70 \%$ of votes that we should use MTX as soon as the diagnosis of RA is made. However, statistical analysis revealed that the strength of recommendation was significantly higher in the first voting (EULAR's unchanged recommendation), so this recommendation was accepted the same as in original EULAR's.

This recommendation was accepted with a strength of recommendation of $9.85 \pm 0.464$ and $100 \%$ of votes. The strength of recommendation in the second voting was $8.77 \pm 2.160$.

9. "In patients responding insufficiently to MTX and/or other csDMARD strategies, with or without glucocorticoids, bDMARDs (TNF inhibitors, abatacept, rituximab or TCZ) should be commenced with MTX."

The strength of recommendation for this item decreased to $9.12 \pm 1.071$ from $9.23 \pm 1.681$. However, this was not statistically significant, so the revised form was accepted since $70 \%$ of the members offered a change in EULAR's original recommendation.

With respect to rituximab, we decided to use it as the first treatment strategy after DMARD failure.

11. "Although EULAR has an opinion regarding tofacitinib, our committee did not suggest any thoughts about tofacitinib as it has not yet been approved in our country."

This statement was approved by a strength of recommendation of $9 \pm 2.135$ and the percentage of participants who voted seven or above for this recommendation was $89 \%$. The strength of recommendation for the first voting for this item was $8.15 \pm 2.111$. There is a statistically significant difference between the first and second voting rounds.

Although we detected no statistically significant differences in the percentage of votes between EULAR's voting and our committee's voting of EULAR recommendations for the items 3 , 9, and 11 (Table 3), we suggested making the changes for these items with the majority of votes.

Our committee approved recommendation seven, which is related with use of low dose glucocorticoids, by $100 \%$ of votes which was much higher than the percentage of votes of EULAR (73\%) (Table 3).

Contrary to the results above, the percentage of votes of our committee for items 8 and 13 were statistically significantly lower than the percentage of EULAR's votes. However, our committee was not required to change these items since the percentage of votes for both items was $96 \%$. The changes made in EULAR's treatment algorithm are shown in Figure 1.

\section{DISCUSSION}

Turkish Compliance and Adaptation of EULAR 2013 RA management recommendations comprise three overarching principles and 14 recommendations. According to EULAR, we have changed three overarching principles and three recommendations, numbers of which are 3, 9, and 11 . The remaining recommendations were unchanged since they were accepted as original statements of EULAR with the majority of votes.

In the overarching principles, we particularly mentioned about the specialists who treat RA patients in our country, adding physiatrists besides rheumatologists since they also treat RA patients.

In item 3, when speaking of "improvement", our committee members of TLAR suggested to add "composite indices" including Clinical Disease Activity Index (CDAI) and Simplified Disease Activity Index (SDAI) since they are the strict indices of remission, as well as to use these indices together with Disease Activity Score 28 (DAS28). 
The use of composite measures of disease activity is also recommended by EULAR. These composite measures include tender and swollen joint counts and the American College of Rheumatology (ACR)/EULAR remission criteria. Our committee advises the use of measures such as SDAI and CDAI as well as DAS28. Although SDAI is superior to define remission compared to DAS28, it may also be used together with DAS28. In a study comparing CDAI and SDAI in RA patients, it was shown that CDAI performed as well as SDAI and the authors recommended CDAI since no acute phase reactant test is necessary, so it's both cheaper and faster. ${ }^{5,6}$

On the other hand, in our country, repayment of bDMARDs is based on DAS28 scores. If a patient with RA has DAS28 score above 5.1, despite use of three different DMARDs for at least three months for each DMARD, bDMARDs can be given. If there is any improvement in DAS28 score of at least 0.6 (for certolizumab, this is 1.2) three months (six months for certolizumab) after starting bDMARD, then bDMARD can be continued for another three months. Then, at the end of this period, if total improvement in DAS28 score is at least 1.2 units, then treatment with bDMARD can be continued for the following six months. If there is no improvement of 1.2 units, bDMARD should be stopped.

However, according to a recent study performed in Turkey, $42.7 \%$ of all RA patients had moderate disease activity based on DAS28 score, thus bDMARDs cannot be given to these patients since there is no reimbursement. ${ }^{7}$

Item 4 was first changed as "methotrexate should be part of the first treatment strategy" at the end of the voting sessions since the committee had a discussion whether the word "active" must be omitted or not. "Active disease" corresponds to the definitions: CDAI $>10$, DAS28 $>3.2$, SDAI $>11,{ }^{8}$ indicating moderate and high disease activity. However, our committee decided that MTX should be given as soon as the diagnosis of RA is made since it is known from clinical studies that 15\% radiologic progression might be seen even if there is remission. ${ }^{9}$ Still, statistical analysis revealed the strength of recommendation of the statement in the original EULAR recommendations to be statistically significantly higher, so we kept the original one.
Also, the committee had concerns about the possible toxicity of high dosages of MTX (25-30 mg). Maximal MTX dose is $25-30 \mathrm{mg}$ for at least eight weeks. ${ }^{10}$ However, in our rheumatology clinics, 25 or $30 \mathrm{mg}$ doses of MTX is usually not reached. If there is insufficient response after reaching 15-20 mg oral doses, higher doses should be given subcutaneously. The general approach is to reduce the dose if any side effects occur. ${ }^{11-13}$ MTX is highly effective both as monotherapy and in combination with glucocorticoids, other csDMARDs, and bDMARDs. ${ }^{14}$ According to ACR criteria, MTX leads to low disease activity or $70 \%$ improvement in DMARD naive patients in six to 12 months. ${ }^{15-22}$

Our committee agreed with the concomitant use of folic acid with MTX $^{21}$ and accepted that the maximum effect of MTX can be reached in up to four to six months. ${ }^{15,17,19,20,22}$ If there is a contraindication for MTX usage, other csDMARDs should be used.

Referring recommendation 9, rituximab can be given as the first bDMARD strategy due to its low cost and favorable safety profile and particularly its efficacy in anti cyclic citrullinated peptide and rheumatoid factor positive patients. So our committee decided to omit the sentence 'rituximab can be given under certain circumstances' which was in the original EULAR recommendations and the sequence of rituximab and TCZ was changed because of the advantages of rituximab as mentioned above. Efficacy of rituximab was shown to be greater in patients with rheumatoid factor and anti cyclic citrullinated peptide positivity than seronegative RA patients. ${ }^{23-25}$

According to Medical Enforcement Declaration in Turkey, rituximab can be given under the circumstances written below:

"In patients with active RA (DAS-28 >5.1), despite use of three different disease modifying antirheumatic drugs or at least one TNF inhibitor treatment for at least three month-period for each drug, rituximab can be prescribed only in university or training and research hospitals with a three month-period report from a board of health consisting of at least one rheumatologist or physiatrist."

The efficacy of rituximab was shown in studies including DANCER, REFLEX, SERENE, and MIRROR studies. ${ }^{26-29}$ 
Rituximab has some advantages such that it can be used in patients with a recent history of lymphoma and demyelinating disease, latent tuberculosis, and patients who live in tuberculosisendemic regions. ${ }^{20,30}$

Risk of serious infections with rituximab is similar with other biologics, most common ones being pneumonia, cellulitis, and urinary tract infections. The levels of immunoglobulins should be assessed before or during treatment with rituximab and after repeated courses of rituximab therapy, since the levels of immunoglobulin $\mathrm{M}$ (IgM) and IgG may decrease, leading to serious infections. This is especially important for patients with low IgG levels. ${ }^{31-34}$

Live vaccines are not recommended for all biologics and this is even more important for rituximab. ${ }^{35}$ Furthermore, all hepatitis tests should be performed before starting rituximab since hepatitis $\mathrm{B}$ may be reactivated. ${ }^{36}$

Tumor necrosis factor inhibitors at the Turkish market based on the order of appearance are listed as follows: IFX, ETN, ADA, golimumab and certolizumab pegol and the biosimilar of IFX, CT-P13. There is no superiority of one bDMARD over the other in terms of efficacy, but there are more data with TNF inhibitors than with other bDMARDs. Therefore, further safety data for recently released bDMARDs are needed.

Certolizumab pegol has also been recently approved in Turkey. ${ }^{37-39}$ Studies have shown certolizumab pegol to be as effective as the other anti-TNF agents. Particularly in pregnancy, certolizumab passes through placenta in smaller amounts than other TNF inhibitors and its level in umbilical cord blood is low. ${ }^{40,41}$

In terms of biosimilars, CT-P13 has been shown to have similar efficacy and safety with the original molecule. ${ }^{42,43}$ It was also approved in our country.

Moreover, our committee agreed with EULAR's committee that all bDMARDs should be used in combination with MTX or other csDMARDs. $10 \mathrm{mg}$ or more/week doses of MTX were shown to be effective when used with TNF inhibitors. ${ }^{44,45}$ Although MTX has some gastrointestinal side effects, it is usually well-tolerated.

Worldwide, 30 to $34 \%$ of patients with RA are using biologics as monotherapy. ${ }^{46-53} \mathrm{TCZ}$ has been found to be superior as monotherapy. ${ }^{54,55}$
In ADACTA study, a comparison of $8 \mathrm{mg} / \mathrm{kg}$ monthly TCZ monotherapy with ADA monotherapy of $40 \mathrm{mg}$ twice a week revealed ACR response rates and change in DAS28 scores to be statistically significantly higher in TCZ treatment group, and adverse event rates to be similar between the groups. This study is a head to head comparison study of TCZ with ADA and the results have shown the potential use of TCZ monotherapy in RA patients. ${ }^{56}$ According to a trial in early RA, only TCZ $(8 \mathrm{mg} / \mathrm{kg})+\mathrm{MTX}$ was clinically, functionally and structurally superior to MTX, but monotherapy of TCZ $8 \mathrm{mg} / \mathrm{kg}$ or a lower dose of TCZ $(4 \mathrm{mg} / \mathrm{kg})+\mathrm{MTX}$ were not superior over MTX. ${ }^{44}$

In ACT-RAY study, TCZ+MTX combination therapy group was compared with TCZ monotherapy group; at $28^{\text {th }}$ week, changes in DAS28 scores and ACR response rates were not statistically significantly different between the groups. ${ }^{57}$ Also, the efficacy of TCZ was shown to increase with time. ${ }^{58}$

Therefore, according to our committee, it is better to choose TCZ if biologic monotherapy is required (e.g. if MTX cannot be used because of its side effects or intolerance). In fact, clinical response is usually continued even if MTX is withheld in patients with established therapy with MTX+TCZ or a TNF-antagonist. ${ }^{59-61}$

In this recommendation, the use of bDMARDs before trying a csDMARD strategy is also discouraged. Some of the patients with early RA respond well to MTX monotherapy as they show $25 \%$ or more ACR70 improvement, so avoiding overtreatment with biologic DMARDs in these patients is important. ${ }^{16,62}$ Also, in the BeSt study, patients using csDMARDS+glucocorticoids were compared with patients using bDMARDs and no statistically significant difference was detected in terms of preliminary clinical, functional, and structural results. ${ }^{62}$ In the IMPROVED trial, use of MTX+low dose glucocorticoids also resulted in high percentage of good outcomes in a short time. ${ }^{16}$ Regardless, it is not possible to use bDMARD as a first treatment strategy in our country due to the restrictions of social security institution. Meanwhile, there are some studies suggesting that starting treatment with antiTNF+MTX in early RA may provide good clinical results even when TNF inhibitor is withheld. ${ }^{63,64}$ 
According to a study by Kádár et al., ${ }^{65}$ the disease activity was low in 27 patients (33.3\%), moderate in 37 patients $(45.7 \%)$ and high in the remaining 17 patients (20.9\%) after 22 months in established RA patients using biologic therapies. Biologic drug was stopped in 20 of the 33 patients (60.6\%) as they entered low disease activity state. And after an average of 16 months of drugfree follow-up, they have maintained this low remission state. Relapse (DAS28 $>5.1$ ) occurred only in five patients (15.1\%) after the withdrawal after an average of 15 months.

In DMARD-naive patients, the BeSt study reported that bDMARD discontinuation was possible particularly in those receiving IFX+MTX as induction therapy compared to those receiving late IFX+MTX combination therapy ( $56 \%$ vs. $29 \%, p=0.008$ in the initial vs. delayed groups, respectively). ${ }^{66}$

In the HIT HARD study, first year clinical outcomes were similar between patients who have stopped ADA after ADA+MTX induction therapy for six months and patients using MTX monotherapy (DAS28: $3.2 \pm 1.4$ vs. $3.4 \pm 1.6, p=0.41$ ). ${ }^{64}$

Furthermore, in the OPTIMA study, most of the patients who achieved low disease activity at six months, remained in low activity state after withdrawal of ADA. Maintenance of low disease activity state was higher in patients who continued to use ADA compared to those who stopped it (at 18 months, $91 \%$ vs. $81 \%$ in the ADA-continue vs. the ADA-stop groups, $p=0.004$, respectively). ${ }^{63}$

Dose reduction in biologics is also possible. In MTX-naive RA, according to the PRIZE study, $2 / 3$ of early RA patients who reached remission with regard to DAS28 (DAS28 <2.6) after one year with ETN $50 \mathrm{mg} /$ week + MTX could maintain this state for two years with half dose ETN (25 mg/week)+MTX. ${ }^{67}$

Moreover, in the PRESERVE study, patients with low disease activity maintained this response after reducing the dose of ETN to $25 \mathrm{mg} /$ week from $50 \mathrm{mg} /$ week+MTX. ${ }^{68}$

The studies in established RA, including Spacing of TNF-blocker Injections in Rheumatoid Arthritis Study (STRASS) and Dose Reduction or Discontinuation of Etanercept in MethotrexateTreated Rheumatoid Arthritis Subjects Who Have
Achieved a Stable Low Disease Activity-State (DOSERA), also showed that dose reduction in TNF inhibitors is possible in RA. ${ }^{69,70}$

AVERT study assessed drug free remission with abatacept in early RA. At 12 months, the percentage of patients in remission (DAS28 <2.6) who were using abatacept + MTX was 60.9\% and the percentage of patients in remission who were using only MTX was $45.2 \%(p=0.010)$. After treatment withdrawal, remissions were $14.8 \%$ vs. $7.8 \%(p=0.045)$ at 12 and 18 months, respectively. ${ }^{71}$

Long-term clinical remission has been shown to be possible in some patients with RA after cessation of TCZ. In a study by Luis AguilarLozano et al., ${ }^{72} 45$ RA patients who were in remission after the last TCZ infusion were assessed. Then, patients were followed every eight weeks for 12 months or until relapse. Of the patients, $44 \%$ maintained remission while relapses were seen in 56\%.

Interleukin-1 inhibitors were shown to be less efficient when compared with other bDMARDs in meta-analyses. So anakinra was not mentioned in the recommendation. Tofacitinib was mentioned in recommendation 11 . We indicated that we did not have any opinion of tofacitinib, but soon after our meeting, tofacitinib was also approved in our country. According to Medical Enforcement Declaration in Turkey, tofacitinib can be given to active RA patients (DAS28 >5.1) despite use of three different disease modifying antirheumatic drugs or at least one TNF inhibitor treatment for at least a three month-period for each drug.

Tofacitinib is a Janus kinase (JAK) inhibitor which is involved in IL-6 signaling and was approved for treatment of RA in more than 20 countries. In Turkey, it is subject to passive repayment which means as soon as it is produced in Turkey, it is going to be repaid. The annual cost of tofacitinib is thought to be similar to a biological agent and it might be cheaper when produced in our country.

Tofacitinib has been shown to be effective in improving clinical, functional and structural outcomes in RA. In a study by Kremer et al., ${ }^{73}$ RA patients who had an inadequate response to, or who could not use MTX, ETN, IFX or 
ADA were given placebo, tofacitinib $5 \mathrm{mg}$, $15 \mathrm{mg}$ or $30 \mathrm{mg}$ twice daily for six weeks. At the end of 12 weeks, the ACR response rates were $70.5 \%, 81.2 \%$ and $76.8 \%$ in the groups receiving tofacitinib 5, 15 and $30 \mathrm{mg}$ respectively. But infection rates were nearly similar in both $15 \mathrm{mg}$ and the $30 \mathrm{mg}$ groups and the placebo group (30.4\% vs. $26.2 \%)$.

In a phase II study by Fleischmann et al., ${ }^{[74]}$ in active RA patients who insufficiently responded to DMARDs, tofacitinib or ADA monotherapy was tested versus placebo. Treatment with tofacitinib with a dose of $\geq 3 \mathrm{mg} 2 \times 1 /$ day ended up with a rapid and significant response compared with placebo (ACR20 responders at week 12 was $39.2 \%$ for $3 \mathrm{mg}$ tofacitinib; $59.2 \%$ for $5 \mathrm{mg}$ tofacitinib; $70.5 \%$ for $10 \mathrm{mg}$ tofacitinib, $71.9 \%$ for $15 \mathrm{mg}$ tofacitinib, $35.9 \%$ of patients for ADA, and $22 \%$ of patients receiving placebo). Most of the adverse events in both tofacitinib and ADA groups were mild or moderate.

In a phase II trial by Kremer et al., ${ }^{75}$ six dosages of oral tofacitinib with placebo were given to active RA patients with an inadequate response to MTX monotherapy. At $12^{\text {th }}$ week, the ACR20 response rates were statistically significantly higher in tofacitinib groups than placebo and improvements continued at 24 weeks. The adverse effects seen in $>10 \%$ of patients in tofacitinib groups were headache, diarrhea, and upper respiratory tract infections. In 21 patients (4.1\%), serious adverse events, increased aspartate transaminase, alanine aminotransferase, cholesterol and serum creatinine levels, and decreased hemoglobin and neutrophil levels were also seen.

In a 12-month, phase III trial, RA patients who were taking MTX were randomly given $5 \mathrm{mg}$ of tofacitinib $2 \times 1 /$ day, $10 \mathrm{mg}$ of tofacitinib $2 \times 1$ /day, $40 \mathrm{mg}$ of ADA/two weeks or placebo. ${ }^{76}$ ACR20 response rates were statistically significantly higher in patients receiving $5 \mathrm{mg}$ or $10 \mathrm{mg}$ of tofacitinib $(51.5 \%$ and $52.6 \%$, respectively) and ADA (47.2\%) than placebo (283\%) at six months $(p<0.001){ }^{76}$ Adverse events were more frequent with tofacitinib than placebo, and in the $10 \mathrm{mg}$ tofacitinib group, two patients developed pulmonary tuberculosis. ${ }^{76}$

However, some safety concerns and its high price precluded recommendation of use of tofacitinib before the failure of at least one and preferably two biologic agents by EULAR, since there is not enough data concerning its long-term safety. Some clinical trials revealed that some serious infections were seen at higher rates in patients using this drug than patients using TNF inhibitors, ${ }^{44,76-79}$ i.e. herpes zoster infections, tuberculosis, and other opportunistic infections have been reported. Also, during the treatment, anemia and lymphocytopenia can be seen and hemoglobin levels do not increase as high as with treatments of csDMARDs and bDMARDs. Therefore, we need more data about clinical experience and safety issues for tofacitinib. Although its efficacy has been shown in various studies, European Medicine Agency has not drawn back its negative opinion about tofacitinib due to its side effects.

In conclusion, Turkish League Against Rheumatism, being a scientific member of EULAR since 1947, has taken on task of adapting the recommendations of EULAR for the rheumatologists and the physiatrists in Turkey. This project is the second study of TLAR in which the opinions of the experts were received about treatment of $\mathrm{RA}$ to generate a countrywide effective, reliable, and sustainable treatment algorithm of RA. This study has shown that Turkish rheumatologists and physiatrists approve most of the EULAR recommendations in treatment of RA. However, some minor changes were done with regard to their experience and also according to the conditions in Turkey. Hereafter our aim is to update the recommendations as new guidelines come up.

\section{Declaration of conflicting interests}

The authors declared no conflicts of interest with respect to the authorship and/or publication of this article.

\section{Funding}

The authors received no financial support for the research and/or authorship of this article.

\section{REFERENCES}

1. Smolen JS, Aletaha D, Koeller M, Weisman MH, Emery P. New therapies for treatment of rheumatoid arthritis. Lancet 2007;370:1861-74. 
2. Smolen JS, van der Heijde D, Machold KP, Aletaha $\mathrm{D}$, Landewé R. Proposal for a new nomenclature of disease-modifying antirheumatic drugs. Ann Rheum Dis 2014;73:3-5.

3. Ataman Ş, Borman P, Evcik D, Aydoğ E, Ayhan F, Yildizlar D, et al. Management of rheumatoid arthritis: consensus recommendations from the Turkish League Against Rheumatism. Turk J Rheumatol 2011;26:273-94.

4. Smolen JS, Landewé R, Breedveld FC, Buch $\mathrm{M}$, Burmester $\mathrm{G}$, Dougados $\mathrm{M}$, et al. EULAR recommendations for the management of rheumatoid arthritis with synthetic and biological diseasemodifying antirheumatic drugs: 2013 update. Ann Rheum Dis 2014;73:492-509.

5. Balsa A, de Miguel E, Castillo C, Peiteado D, MartínMola E. Superiority of SDAI over DAS-28 in assessment of remission in rheumatoid arthritis patients using power Doppler ultrasonography as a gold standard. Rheumatology (Oxford) 2010;49:683-90.

6. Aletaha D, Smolen J. The Simplified Disease Activity Index (SDAI) and the Clinical Disease Activity Index (CDAI): a review of their usefulness and validity in rheumatoid arthritis. Clin Exp Rheumatol 2005;23:100-8.

7. Bal A, Ataman Ş, Bodur H, Rezvani A, Paker N, Tastekin N, et al. Characteristics of patients with rheumatoid arthritis in Turkey: results from the Turkish League Against Rheumatism Rheumatoid arthritis registry. Arch Rheumatol 2015;30:1-8.

8. Aletaha D, Landewe R, Karonitsch T, Bathon J, Boers $\mathrm{M}$, Bombardier $\mathrm{C}$, et al. Reporting disease activity in clinical trials of patients with rheumatoid arthritis: EULAR/ACR collaborative recommendations. Arthritis Rheum 2008;59:1371-7.

9. Smolen JS, Han C, van der Heijde DM, Emery P, Bathon JM, Keystone E, et al. Radiographic changes in rheumatoid arthritis patients attaining different disease activity states with methotrexate monotherapy and infliximab plus methotrexate: the impacts of remission and tumour necrosis factor blockade. Ann Rheum Dis 2009;68:823-7.

10. Visser K, van der Heijde D. Optimal dosage and route of administration of methotrexate in rheumatoid arthritis: a systematic review of the literature. Ann Rheum Dis 2009;68:1094-9.

11. Gutierrez-Ureña S, Molina JF, García CO, Cuéllar ML, Espinoza LR. Pancytopenia secondary to methotrexate therapy in rheumatoid arthritis. Arthritis Rheum 1996;39:272-6.

12. Kremer JM, Alarcón GS, Weinblatt ME, Kaymakcian MV, Macaluso M, Cannon GW, et al. Clinical, laboratory, radiographic, and histopathologic features of methotrexate-associated lung injury in patients with rheumatoid arthritis: a multicenter study with literature review. Arthritis Rheum 1997;40:1829-37.

13. Walker AM, Funch D, Dreyer NA, Tolman KG, Kremer JM, Alarcón GS, et al. Determinants of serious liver disease among patients receiving lowdose methotrexate for rheumatoid arthritis. Arthritis Rheum 1993;36:329-35.

14. Pincus T, Yazici Y, Sokka T, Aletaha D, Smolen JS. Methotrexate as the "anchor drug" for the treatment of early rheumatoid arthritis. Clin Exp Rheumatol 2003;21:179-85.

15. Breedveld FC, Weisman MH, Kavanaugh AF, Cohen SB, Pavelka K, van Vollenhoven $\mathrm{R}$, et al. The PREMIER study: A multicenter, randomized, double-blind clinical trial of combination therapy with adalimumab plus methotrexate versus methotrexate alone or adalimumab alone in patients with early, aggressive rheumatoid arthritis who had not had previous methotrexate treatment. Arthritis Rheum 2006;54:26-37.

16. Heimans L, Wevers-de Boer KV, Visser K, Goekoop RJ, van Oosterhout M, Harbers JB, et al. A two-step treatment strategy trial in patients with early arthritis aimed at achieving remission: the IMPROVED study. Ann Rheum Dis 2014;73:1356-61.

17. Klareskog L, van der Heijde D, de Jager JP, Gough A, Kalden J, Malaise M, et al. Therapeutic effect of the combination of etanercept and methotrexate compared with each treatment alone in patients with rheumatoid arthritis: double-blind randomised controlled trial. Lancet 2004;363:675-81.

18. Salliot C, van der Heijde D. Long-term safety of methotrexate monotherapy in patients with rheumatoid arthritis: a systematic literature research. Ann Rheum Dis 2009;68:1100-4.

19. St Clair EW, van der Heijde DM, Smolen JS, Maini RN, Bathon JM, Emery P, et al. Combination of infliximab and methotrexate therapy for early rheumatoid arthritis: a randomized, controlled trial. Arthritis Rheum 2004;50:3432-43.

20. Tak PP, Rigby WF, Rubbert-Roth A, Peterfy CG, van Vollenhoven RF, Stohl W, et al. Inhibition of joint damage and improved clinical outcomes with rituximab plus methotrexate in early active rheumatoid arthritis: the IMAGE trial. Ann Rheum Dis 2011;70:39-46.

21. van Ede AE, Laan RF, Rood MJ, Huizinga TW, van de Laar MA, van Denderen CJ, et al. Effect of folic or folinic acid supplementation on the toxicity and efficacy of methotrexate in rheumatoid arthritis: a forty-eight week, multicenter, randomized, doubleblind, placebo-controlled study. Arthritis Rheum 2001;44:1515-24.

22. Westhovens R, Robles M, Ximenes AC, Nayiager S, Wollenhaupt J, Durez P, et al. Clinical efficacy and safety of abatacept in methotrexate-naive patients with early rheumatoid arthritis and poor prognostic factors. Ann Rheum Dis 2009;68:1870-7.

23. Dörner $T$, Isenberg $D$, Jayne $D$, Wiendl $H$, Zillikens D, Burmester G. Current status on B-cell depletion therapy in autoimmune diseases other than rheumatoid arthritis. Autoimmun Rev 2009;9:82-9. 
24. Chatzidionysiou $\mathrm{K}$, Lie $\mathrm{E}$, Nasonov $\mathrm{E}$, Lukina G, Hetland ML, Tarp U, et al. Highest clinical effectiveness of rituximab in autoantibody-positive patients with rheumatoid arthritis and in those for whom no more than one previous TNF antagonist has failed: pooled data from 10 European registries. Ann Rheum Dis 2011;70:1575-80.

25. Kekow J, Mueller-Ladner U, Schulze-Koops $H$. Rituximab is more effective than second anti-TNF therapy in rheumatoid arthritis patients and previous TNF $\alpha$ blocker failure. Biologics 2012;6:191-9.

26. Mease PJ, Revicki DA, Szechinski J, Greenwald M, Kivitz A, Barile-Fabris L, et al. Improved health-related quality of life for patients with active rheumatoid arthritis receiving rituximab: Results of the DoseRanging Assessment: International Clinical Evaluation of Rituximab in Rheumatoid Arthritis (DANCER) Trial. J Rheumatol 2008;35:20-30.

27. Keystone EC, Cohen SB, Emery P, Kremer JM, Dougados M, Loveless JE, et al. Multiple courses of rituximab produce sustained clinical and radiographic efficacy and safety in patients with rheumatoid arthritis and an inadequate response to 1 or more tumor necrosis factor inhibitors: 5-year data from the REFLEX study. J Rheumatol 2012;39:2238-46.

28. Khan A, Scott D. Rituximab after methotrexate failure in rheumatoid arthritis: evaluation of the SERENE trial. Expert Opin Biol Ther 2011;11:1515-8.

29. Rubbert-Roth A, Tak PP, Zerbini C, Tremblay JL, Carreño L, Armstrong G, et al. Efficacy and safety of various repeat treatment dosing regimens of rituximab in patients with active rheumatoid arthritis: results of a Phase III randomized study (MIRROR). Rheumatology (Oxford) 2010;49:1683-93.

30. Emery P, Fleischmann R, Filipowicz-Sosnowska A, Schechtman J, Szczepanski L, Kavanaugh A, et al. The efficacy and safety of rituximab in patients with active rheumatoid arthritis despite methotrexate treatment: results of a phase IIB randomized, doubleblind, placebo-controlled, dose-ranging trial. Arthritis Rheum 2006;54:1390-400.

31. Gottenberg JE, Ravaud P, Bardin T, Cacoub P, Cantagrel A, Combe B, et al. Risk factors for severe infections in patients with rheumatoid arthritis treated with rituximab in the autoimmunity and rituximab registry. Arthritis Rheum 2010;62:2625-32.

32. De La Torre I, Leandro MJ, Valor L, Becerra E, Edwards JC, Cambridge G. Total serum immunoglobulin levels in patients with RA after multiple B-cell depletion cycles based on rituximab: relationship with B-cell kinetics. Rheumatology (Oxford) 2012;51:833-40.

33. van Vollenhoven RF, Emery P, Bingham CO 3rd, Keystone EC, Fleischmann RM, Furst DE, et al. Longterm safety of rituximab in rheumatoid arthritis: 9.5year follow-up of the global clinical trial programme with a focus on adverse events of interest in RA patients. Ann Rheum Dis 2013;72:1496-502.
34. Westra J, van Assen S, Wilting KR, Land J, Horst G, de Haan A, et al. Rituximab impairs immunoglobulin (Ig)M and IgG (subclass) responses after influenza vaccination in rheumatoid arthritis patients. Clin Exp Immunol 2014;178:40-7.

35. Keyser FD. Choice of Biologic Therapy for Patients with Rheumatoid Arthritis: The Infection Perspective. Curr Rheumatol Rev 2011;7:77-87.

36. Gigi E, Georgiou T, Mougiou D, Boura P, RaptopoulouGigi M. Hepatitis B reactivation in a patient with rheumatoid arthritis with antibodies to hepatitis B surface antigen treated with rituximab. Hippokratia 2013;17:91-3.

37. Keystone $\mathrm{E}$, Landewé $\mathrm{R}$, van Vollenhoven $\mathrm{R}$, Combe $\mathrm{B}$, Strand V, Mease P, et al. Long-term safety and efficacy of certolizumab pegol in combination with methotrexate in the treatment of rheumatoid arthritis: 5-year results from the RAPID 1 trial and open-label extension. Ann Rheum Dis 2014;73:2094-100.

38. Strand V, Smolen JS, van Vollenhoven RF, Mease P, Burmester GR, Hiepe F, et al. Certolizumab pegol plus methotrexate provides broad relief from the burden of rheumatoid arthritis: analysis of patientreported outcomes from the RAPID 2 trial. Ann Rheum Dis 2011;70:996-1002.

39. Fleischmann R, Vencovsky J, van Vollenhoven RF, Borenstein D, Box J, Coteur G, et al. Efficacy and safety of certolizumab pegol monotherapy every 4 weeks in patients with rheumatoid arthritis failing previous disease-modifying antirheumatic therapy: the FAST4WARD study. Ann Rheum Dis 2009;68:805-11.

40. Stephens S, Brown D, Nesbitt A, Foulkes B. Lack of placental transfer and accumulation in milk of an anti-TNF PEGylated Fab' fragment in rats. J Crohn's Colitis 2007;1:43.

41. Mahadevan U, Abreu MT. Certolizumab use in pregnancy: low levels detected in cord blood. Gastroenterology 2009;136:146.

42. Yoo DH, Hrycaj P, Miranda P, Ramiterre E, Piotrowski $\mathrm{M}$, Shevchuk S, et al. A randomised, double-blind, parallel-group study to demonstrate equivalence in efficacy and safety of CT-P13 compared with innovator infliximab when coadministered with methotrexate in patients with active rheumatoid arthritis: the PLANETRA study. Ann Rheum Dis 2013;72:1613-20.

43. Park W, Hrycaj P, Jeka S, Kovalenko V, Lysenko G, Miranda P, et al. A randomised, double-blind, multicentre, parallel-group, prospective study comparing the pharmacokinetics, safety, and efficacy of CT-P13 and innovator infliximab in patients with ankylosing spondylitis: the PLANETAS study. Ann Rheum Dis 2013;72:1605-12.

44. Burmester GR, Rigby W, Van Vollenhoven RF, Kay J, Rubbert-Roth A, Kelman A, et al. Tocilizumab in combination therapy and monotherapy versus methotrexate in methotrexate-naive patients with early rheumatoid arthritis: clinical and radiographic outcomes from a randomized, placebo-controlled trial. 
Arthritis Rheum 2013;65:2767.

45. Krieckaert CL, Nurmohamed MT, Wolbink GJ. Methotrexate reduces immunogenicity in adalimumab treated rheumatoid arthritis patients in a dose dependent manner. Ann Rheum Dis 2012;71:1914-5.

46. Heiberg MS, Koldingsnes W, Mikkelsen K, Rødevand $\mathrm{E}$, Kaufmann C, Mowinckel P, et al. The comparative one-year performance of anti-tumor necrosis factor alpha drugs in patients with rheumatoid arthritis, psoriatic arthritis, and ankylosing spondylitis: results from a longitudinal, observational, multicenter study. Arthritis Rheum 2008;59:234-40.

47. Soliman MM, Ashcroft DM, Watson KD, Lunt M, Symmons DP, Hyrich KL. Impact of concomitant use of DMARDs on the persistence with anti-TNF therapies in patients with rheumatoid arthritis: results from the British Society for Rheumatology Biologics Register. Ann Rheum Dis 2011;70:583-9.

48. Listing J, Strangfeld A, Rau R, Kekow J, GromnicaIhle $\mathrm{E}$, Klopsch $\mathrm{T}$, et al. Clinical and functional remission: even though biologics are superior to conventional DMARDs overall success rates remain low--results from RABBIT, the German biologics register. Arthritis Res Ther 2006;8:66.

49. Askling J, Fored CM, Brandt L, Baecklund E, Bertilsson L, Feltelius N, et al. Time-dependent increase in risk of hospitalisation with infection among Swedish RA patients treated with TNF antagonists. Ann Rheum Dis 2007;66:1339-44.

50. Mariette X, Gottenberg JE, Ravaud P, Combe B. Registries in rheumatoid arthritis and autoimmune diseases: data from the French registries. Rheumatology (Oxford) 2011;50:222-9.

51. Yazici Y, Shi N, John A. Utilization of biologic agents in rheumatoid arthritis in the United States: analysis of prescribing patterns in 16,752 newly diagnosed patients and patients new to biologic therapy. Bull NYU Hosp Jt Dis 2008;66:77-85.

52. Lee SJ, Chang H, Yazici Y, Greenberg JD, Kremer JM, Kavanaugh A. Utilization trends of tumor necrosis factor inhibitors among patients with rheumatoid arthritis in a United States observational cohort study. J Rheumatol 2009;36:1611-7.

53. Sarzi-Puttini P, Antivalle M, Marchesoni A, Favalli EG, Gorla R, Filippini M, et al. Efficacy and safety of anti-TNF agents in the Lombardy rheumatoid arthritis network (LORHEN). Reumatismo 2008;60:290-5.

54. Jones G, Sebba A, Gu J, Lowenstein MB, Calvo A, Gomez-Reino JJ, et al. Comparison of tocilizumab monotherapy versus methotrexate monotherapy in patients with moderate to severe rheumatoid arthritis: the AMBITION study. Ann Rheum Dis 2010;69:88-96.

55. Nishimoto N, Hashimoto J, Miyasaka N, Yamamoto $\mathrm{K}$, Kawai S, Takeuchi $\mathrm{T}$, et al. Study of active controlled monotherapy used for rheumatoid arthritis, an IL-6 inhibitor (SAMURAI): evidence of clinical and radiographic benefit from an $\mathrm{x}$ ray readerblinded randomised controlled trial of tocilizumab.
Ann Rheum Dis 2007:66:1162-7.

56. Gabay C, Emery P, van Vollenhoven R, Dikranian A, Alten R, Pavelka K, et al. Tocilizumab monotherapy versus adalimumab monotherapy for treatment of rheumatoid arthritis (ADACTA): a randomised, double-blind, controlled phase 4 trial. Lancet 2013;381:1541-50.

57. Huizinga TW, Conaghan PG, Martin-Mola E, Schett G, Amital H, Xavier RM, et al. Clinical and radiographic outcomes at 2 years and the effect of tocilizumab discontinuation following sustained remission in the second and third year of the ACT-RAY study. Ann Rheum Dis 2015;74:35-43.

58. Smolen J, Gomez-Reino JJ, Vernon E, RubbertRoth A, Emery P. Efficacy of Tocilizumab in patients with RA and inadequate response to DMARDs or TNF inhibitors: Up to 3.5-year data from ongoing extension studies. Ann Rheum Dis 2010;69:542.

59. Dougados M, Kissel K, Sheeran T, Tak PP, Conaghan PG, Mola EM, et al. Adding tocilizumab or switching to tocilizumab monotherapy in methotrexate inadequate responders: 24-week symptomatic and structural results of a 2-year randomised controlled strategy trial in rheumatoid arthritis (ACT-RAY). Ann Rheum Dis 2013;72:43-50.

60. Emery P, Kvien TK, Combe B, Freundlich B, Robertson $\mathrm{D}$, Ferdousi $\mathrm{T}$, et al. Combination etanercept and methotrexate provides better disease control in very early ( $<=4$ months) versus early rheumatoid arthritis ( $>4$ months and $<2$ years): post hoc analyses from the COMET study. Ann Rheum Dis 2012;71:989-92.

61. van Riel PL, Taggart AJ, Sany J, Gaubitz M, Nab HW, Pedersen R, et al. Efficacy and safety of combination etanercept and methotrexate versus etanercept alone in patients with rheumatoid arthritis with an inadequate response to methotrexate: the ADORE study. Ann Rheum Dis 2006;65:1478-83.

62. Goekoop-Ruiterman YP, de Vries-Bouwstra JK, Allaart CF, van Zeben D, Kerstens PJ, Hazes JM, et al. Clinical and radiographic outcomes of four different treatment strategies in patients with early rheumatoid arthritis (the BeSt study): a randomized, controlled trial. Arthritis Rheum 2005;52:3381-90.

63. Kavanaugh A, Fleischmann RM, Emery P, Kupper $\mathrm{H}$, Redden L, Guerette B, et al. Clinical, functional and radiographic consequences of achieving stable low disease activity and remission with adalimumab plus methotrexate or methotrexate alone in early rheumatoid arthritis: 26-week results from the randomised, controlled OPTIMA study. Ann Rheum Dis 2013;72:64-71.

64. Detert J, Bastian H, Listing J, Weiß A, Wassenberg $\mathrm{S}$, Liebhaber $\mathrm{A}$, et al. Induction therapy with adalimumab plus methotrexate for 24 weeks followed by methotrexate monotherapy up to week 48 versus methotrexate therapy alone for DMARDnaive patients with early rheumatoid arthritis: HIT 
HARD, an investigator-initiated study. Ann Rheum Dis 2013;72:844-50.

65. Kádár G, Balázs E, Soós B, Laduver A, Keszthelyi $\mathrm{P}$, Szekanecz Z, et al. Disease activity after the discontinuation of biological therapy in inflammatory rheumatic diseases. Clin Rheumatol 2014;33:329-33.

66. van der Kooij SM, le Cessie S, Goekoop-Ruiterman YP, de Vries-Bouwstra JK, van Zeben D, Kerstens $\mathrm{PJ}$, et al. Clinical and radiological efficacy of initial vs delayed treatment with infliximab plus methotrexate in patients with early rheumatoid arthritis. Ann Rheum Dis 2009;68:1153-8.

67. Emery $\mathrm{P}$, Hammoudeh $\mathrm{M}$, Fitzgerald $\mathrm{O}$, Combe B, Martin Mola E, Bukowski J, et al. Assessing maintenance of remission with reduced dose etanercept plus methotrexate, methotrexate alone, or placebo in patients with early rheumatoid arthritis who achieved remission with etanercept and methotrextate: the PRIZE study. Ann Rheum Dis 2013;72:399.

68. Smolen JS, Nash P, Durez P, Hall S, Ilivanova E, Irazoque-Palazuelos $F$, et al. Maintenance, reduction, or withdrawal of etanercept after treatment with etanercept and methotrexate in patients with moderate rheumatoid arthritis (PRESERVE): a randomised controlled trial. Lancet 2013;381:918-29.

69. Fautrel B, Gandjbakhch F, Foltz V, Pham T, Morel $\mathrm{J}$, Alfaiate $\mathrm{T}$, et al. Targeting the lowest efficacious dose for rheumatoid arthritis patients in remission: clinical and structural impact of a stepdown strategy trial based on progressive spacing of TNFblocker injections (STRASS trial). Ann Rheum Dis 2013;72:72.

70. Ostergaard M, Leirisalo-Repo M, Uhlig T, Jansson $\mathrm{M}$, Larsson $\mathrm{E}$, Brock $\mathrm{F}$, et al. In rheumatoid arthritis patients with stable low disaese activity on methotrexate plus etanercept, continuation of etanercept is superior both clinically and radiographically to discontinuation: results from a randomized, 3-armed, double-blind clinical trial. Arthritis Rheum. 2013;66:1017.

71. Emery P, Burmester GR, Bykerk VP, Combe BG, Furst DE, Barré E, et al. Evaluating drug-free remission with abatacept in early rheumatoid arthritis: results from the phase $3 \mathrm{~b}$, multicentre, randomised, active-controlled AVERT study of 24 months, with a 12-month, double-blind treatment period. Ann Rheum Dis 2015;74:19-26.
72. Aguilar-Lozano L, Castillo-Ortiz JD, Vargas-Serafin C, Morales-Torres J, Sanchez-Ortiz A, SandovalCastro $\mathrm{C}$, et al. Sustained clinical remission and rate of relapse after tocilizumab withdrawal in patients with rheumatoid arthritis. J Rheumatol 2013;40:1069-73.

73. Kremer JM, Bloom BJ, Breedveld FC, Coombs $\mathrm{JH}$, Fletcher MP, Gruben D, et al. The safety and efficacy of a JAK inhibitor in patients with active rheumatoid arthritis: Results of a double-blind, placebo-controlled phase Ila trial of three dosage levels of CP-690,550 versus placebo. Arthritis Rheum 2009;60:1895-905.

74. Fleischmann R, Cutolo M, Genovese MC, Lee EB, Kanik KS, Sadis S, et al. Phase Ilb dose-ranging study of the oral JAK inhibitor tofacitinib (CP-690,550) or adalimumab monotherapy versus placebo in patients with active rheumatoid arthritis with an inadequate response to disease-modifying antirheumatic drugs. Arthritis Rheum 2012;64:617-29.

75. Kremer JM, Cohen S, Wilkinson BE, Connell CA, French JL, Gomez-Reino J, et al. A phase IIb doseranging study of the oral JAK inhibitor tofacitinib (CP-690,550) versus placebo in combination with background methotrexate in patients with active rheumatoid arthritis and an inadequate response to methotrexate alone. Arthritis Rheum 2012;64:970-81.

76. van Vollenhoven RF, Fleischmann R, Cohen S, Lee EB, García Meijide JA, Wagner S, et al. Tofacitinib or adalimumab versus placebo in rheumatoid arthritis. $\mathrm{N}$ Engl J Med 2012;367:508-19.

77. Fleischmann R, Kremer J, Cush J, Schulze-Koops H, Connell CA, Bradley JD, et al. Placebo-controlled trial of tofacitinib monotherapy in rheumatoid arthritis. N Engl J Med 2012;367:495-507.

78. van der Heijde D, Tanaka Y, Fleischmann R, Keystone E, Kremer J, Zerbini C, et al. Tofacitinib (CP-690,550) in patients with rheumatoid arthritis receiving methotrexate: twelve-month data from a twentyfour-month phase III randomized radiographic study. Arthritis Rheum 2013;65:559-70.

79. Lee EB, Fleischmann RM, Hall S, Wilkinson B, Bradley JD, Gruben D, et al. Radiographic, clinical and functional comparison of tofacitinib monotherapy versus methotrexate in methotrexate-naive patients with rheumatoid arthritis. Arthritis Rheum 2012;64:1049. 